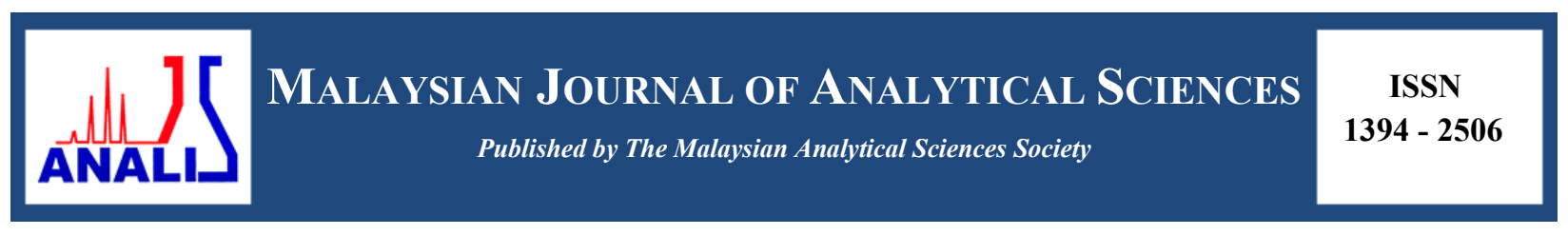

\title{
DODECYLBENZENE SULFONIC ACID CONCENTRATION EFFECT ON ELECTRICAL AND THERMAL PROPERTIES OF POLYANILINE
}

\section{(Kesan Penumpuan Asid Sulfonik Dodekilbenzena ke atas Sifat Elektrik dan Termal Polianilin)}

\author{
Nurul Akmil Mustaffa ${ }^{1 *}$, Qumrul Ahsan ${ }^{1}$, Mohd Asyadi Azam ${ }^{1}$, Luqman Chuah Abdullah ${ }^{2}$ \\ ${ }^{I}$ Faculty of Manufacturing Engineering, \\ Universiti Teknikal Malaysia Melaka, Hang Tuah Jaya, 76100 Durian Tunggal, Melaka, Malaysia \\ ${ }^{2}$ Material Processing and Technology Laboratory, Institute of Advance Technology, \\ Universiti Putra Malaysia, 42400 UPM Serdang, Selangor, Malaysia \\ *Corresponding author: akmil.mustaffa@gmail.com
}

Received: 28 November 2016; Accepted: 5 February 2017

\begin{abstract}
Polyaniline (PANI) doped with various concentration of dedocylbenzene sulfonate acid (DBSA) were prepared by oxidative polymerization with presence of ammonium persulfate. Emerald green PANI powder obtained were characterized by Fourier transform infrared spectroscopy (FTIR), differential scanning calorimetry (DSC), and carried out electrical conductivity test. In this research, the conductivity and thermal properties of PANI has been changed with the effect of doping. With increasing concentration of DBSA, the conductivity raises up to certain concentration (1.65 mmol of DBSA), afterwards with further increase of DBSA concentration, conductivity value declines and reaches to a value lower than that of pristine PANI. The similar trend is also observed for enthalpy values $(\Delta \mathrm{H})$ determined by DSC of pristine PANI and DBSA doped PANIs' which may attribute the effect of concentration of DBSA on molecular arrangement in PANI. Results from polymeric structure obtained from FTIR clearly indicate the disruption in bond when PANI doped with DBSA and it may indicate that the DBSA changes molecule structure of PANI in term of segmented local structure of polymer.
\end{abstract}

Keywords: polyaniline, advanced material, dodecylbenzene sulfonate acid, conductivity, differential scanning calorimetry

\begin{abstract}
Abstrak
Polianilin (PANI) didopkan dengan pelbagai kepekatan asid sulfonat dodekilbenzena (DBSA) telah disediakan dengan kaedah pempolimeran oksidatif dengan kehadiran ammonium persulfat. Serbuk hijau zamrud PANI yang diperolehi dicirikan oleh spektroskopi inframerah Fourier (FTIR), kalorimeter imbasan pembeza (DSC), dan ukuran kekonduksian. Dalam kajian ini, didapati bahawa kekonduksian haba dan sifat - sifat PANI telah ditukar sebagai kesan daripada pendopan. Dengan peningkatan kepekatan DBSA, kekonduksian juga meningkat sehingga kepekatan tertentu (1.65 mmol daripada DBSA). Kemudian, kekonduksian berkurangan dengan peningkatan kepekatan DBSA selanjutnya. Keputusan PANI daripada DSC, yang mengandungi nilai entalpi yang berbeza $(\Delta \mathrm{H})$ menunjukkan bahawa DBSA tidak mengubah struktur molekul PANI dari segi segmen struktur tempatan polimer dan $\Delta \mathrm{H}$ juga menunjukkan ke arah kesan kepekatan DBSA pada susunan molekul dalam PANI.
\end{abstract}

Kata kunci: polianilin, bahan termaju, asid sulfonat dodekilbenzena, konduktiviti, kalorimeter imbasan pembeza

\section{Introduction}

Now days, conductive polymers are widely used in electric and electronic devices. Among the conductive polymers, polyaniline (PANI) conquers a place of special interest in alternative to metal and semiconducting material [1]. 
Through the past 20 years, a variety of different conducting polymers have been found and studied [2]. From the commercial viewpoint, these polymers show promise for the invention of materials for numerous applications; they be able to replace metals and semiconductors, because their feature in conductivity, low density, and easy processability. Polyaniline (PANI) a representatives from the family of conducting polymers is well-known by easy synthesis and high environmental stability. Interest about PANI (Figure 1) is evidenced by the fact that the field of conducting polymers has concerned scientists from such varied areas of interest as electrochemistry, materials science, synthetic chemistry, polymer science, solid state physics, electrical and electronics engineering.

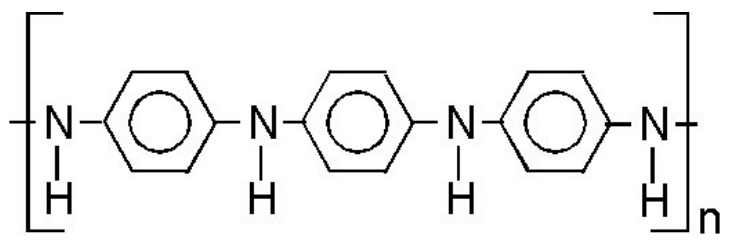

Figure 1. Polyaniline molecule structure

The attention has been paid in studying conducting polymers because these polymers have aromatic rings - and nitrogen-substituted derivatives which can be readily synthesized. Rings and derivatives can exist in several different oxidation states these in principle can be doped by various dopants through non-redox processes or by partial chemical or electrochemical oxidation. DBSA has been widely used as dopant which also acts as a surfactant and a protonating agent [3], especially in emulsion polymerizations [4] where the PANI performs as a semiconductor. Preparation of PANI-DBSA colloids [5] to polymerize PANI is a doping process for adding impurities to intrinsic semiconductors (PANI) to change their electrical properties. However, the doping process sometime will affect directly or indirectly to the conductivity of PANI. Hence, the concentration of dopant also have maximum limit that will contribute to lower in conductivity because of the restricted electron delocalization. The study of polymeric materials by thermal analysis has become increasingly popular in today's analytical laboratory because it will give more information about molecule arrangement and defect in crystal structure.

Therefore, in this research focusing more on the DBSA effect without using strong acid to alter the acidic condition of PANI during polymerization. DBSA doped PANI were characterized using four point probe method for conductivity, differential scanning calorimeter (DSC) for thermal analysis and Fourier Transforms Infrared spectrometer (FTIR).

\section{Materials}

\section{Materials and Methods}

Aniline chloride and hydrochloric acid $(\mathrm{HCl})(37 \%)$ were collected from Merck, Ammonium peroxydisulfate and dodecylbenzene sulfonic acid $\left(\mathrm{C}_{18} \mathrm{H}_{30} \mathrm{NaO}_{3} \mathrm{~S}\right)$ were collected from Sigma-Aldrich.

\section{Synthesis of PANI}

The pristine PANI was synthesized (direct oxidation) by the polymerization of aniline hydrochloride and ammonium peroxydisulfate without addition of dodecylbenzene sulfonic acid (DBSA). The aniline hydrochloride and ammonium peroxydisulphate $\left(\left(\mathrm{NH}_{4}\right)_{2} \mathrm{~S}_{2} \mathrm{O}_{8}\right)$ was dissolved in $100 \mathrm{~mL}$ of distilled water separately. Both solutions were precooled at $9{ }^{\circ} \mathrm{C}$ for 12 hours and were mixed in a beaker, briefly stirred and left at rest to polymerize in a refrigerator at $9{ }^{\circ} \mathrm{C}$ for 24 hours. While for DBSA doped PANI was synthesized by the polymerization of aniline hydrochloride in different concentrations of aqueous DBS acid solutions. Aniline hydrochloride (purum; $5.18 \mathrm{~g}, 40 \mathrm{mmol}$ ) was added in aqueous DBS acids $(0.8,1.65,2.0$, and $2.5 \mathrm{mmol})$ of $100 \mathrm{~mL}$ solution. The reaction conditions for synthesis of PANI-DBSA are given in Table 1. Ammonium peroxydisulphate (purum; $11.42 \mathrm{~g}, 50 \mathrm{mmol}$ ) was dissolved in distilled water to prepare another $100 \mathrm{~mL}$ of solution. Both solutions were precooled $\left(9{ }^{\circ} \mathrm{C}, 12\right.$ hours) and were mixed in a beaker, briefly stirred, and left at rest to polymerize in refrigerator at $9{ }^{\circ} \mathrm{C}$ for 24 hours. Afterwards the PANI precipitate (emeraldine salt) was collected on a filter, washed three times with $100 \mathrm{ml}$ of $0.2 \mathrm{M} \mathrm{HCl}$ acid followed by $100 \mathrm{~mL}$ of acetone. Later salt was dried in vacuum at $60{ }^{\circ} \mathrm{C}$ for 24 hours. 
Table 1. Reaction conditions for synthesis of PANI-DBSA

\begin{tabular}{llllcc}
\hline Code & Monomer & Oxidant & Dopant & $\begin{array}{c}\text { Volume of Dopant } \\
\text { (mmol) }\end{array}$ & Temperature \\
\hline $\mathrm{DBSA}_{1}$ & & & & 0.8 & \\
$\mathrm{DBSA}_{2}$ & & & & 1.2 & \\
$\mathrm{DBSA}_{3}$ & Aniline & $\left(\mathrm{NH}_{4}\right)_{2} \mathrm{~S}_{2} \mathrm{O}_{8}$ & $\mathrm{C}_{18} \mathrm{H}_{30} \mathrm{NaO}_{3} \mathrm{~S}$ & 1.6 & $9{ }^{\circ} \mathrm{C}$ \\
$\mathrm{DBSA}_{4}$ & & & & 2.0 & \\
$\mathrm{DBSA}_{5}$ & & & & 2.5 & \\
\hline
\end{tabular}

Characterization: Fourier Transformation Infrared analysis

FTIR (FT/IR-6100; JASCO) analysis was conducted to confirm the presence of functional group in pristine PANI and PANI-DBSA. PANI granules powder was grounded to obtain fine particles. All spectra were recorded at ambient temperature and the analysis was performed at wavelength range from $400 \mathrm{~cm}^{-1}$ to $4000 \mathrm{~cm}^{-1}$ at scanning speed of $2 \mathrm{~mm} \mathrm{~s}^{-1}$ with aperture size of $7.1 \mathrm{~mm}$.

\section{Conductivity}

For conductivity measurement, PANI powders are firstly press into a pellet form by using hydraulic presser to make less than $1 \mathrm{~mm}$ samples. Then, conductivity measurements, using the four-point probe technique (ASTM D-991-89) were performed upon pressed pellets of the starting material. The measurements were made using a Jandel fourpoint probe.

\section{Thermal scanning}

Differential Scanning Calorimetry (Perkin Elmer model DSC 7) were conducted in nitrogen atmosphere at a temperature range of $30-300{ }^{\circ} \mathrm{C}$ with a heating rate of $20{ }^{\circ} \mathrm{C} / \mathrm{min}$

\section{Fourier transforms infrared spectroscopy}

\section{Results and Discussion}

FTIR is used to observe the changes in PANI bonding structure. From Figure 2, the strong peak observed at $\sim 1600$ $\mathrm{cm}^{-1}$ is related to $\mathrm{C}=\mathrm{C}$ conjugate. This peaks are shown in pristine PANI, PANI-DBSA ${ }_{3}$ and PANI-DBSA at $_{5} 1608$, 1617 and $1612 \mathrm{~cm}^{-1}$, respectively. The adsorption band at around $1380 \mathrm{~cm}^{-1}$ (blue circle) corresponds to group of sulphoamide formed after doping with DBSA, for that reason only PANI-DBSA 3 AND PANI-DBSA 5 spectra shows slightly broad peaks base on sulphoamide structure present in their molecule. The major peaks at $1360-1250$ $\mathrm{cm}^{-1}$ correspond to quinone and benzene ring stretching deformations as correspond to aromatic amide in PANI structure. The adsorption band at $1306 \mathrm{~cm}^{-1}$ corresponds to $\pi$-electron delocalization induced in polymer via protonation. The PANI-DBSA 3 and PANI-DBSA 5 spectra also show the adsorption band correspond to covalent sulphonates at 1095 and $1084 \mathrm{~cm}^{-1}$ as shown in the red circle. The main functional group of PANI is 1,4disubstituded benzene which found at 820,814 , and $810 \mathrm{~cm}^{-1}$ for pristine PANI, PANI-DBSA 3 and PANI-DBSA, respectively. The various peaks in the range of 700 to $500 \mathrm{~cm}^{-1}$ are correspond to main aromatic component of PANI's. Table 2, shows the absorption FTIR peaks collected from pristine PANI, PANI-DBSA 3 and PANI-DBSA $_{5}$ as compare to reference values [6]. 


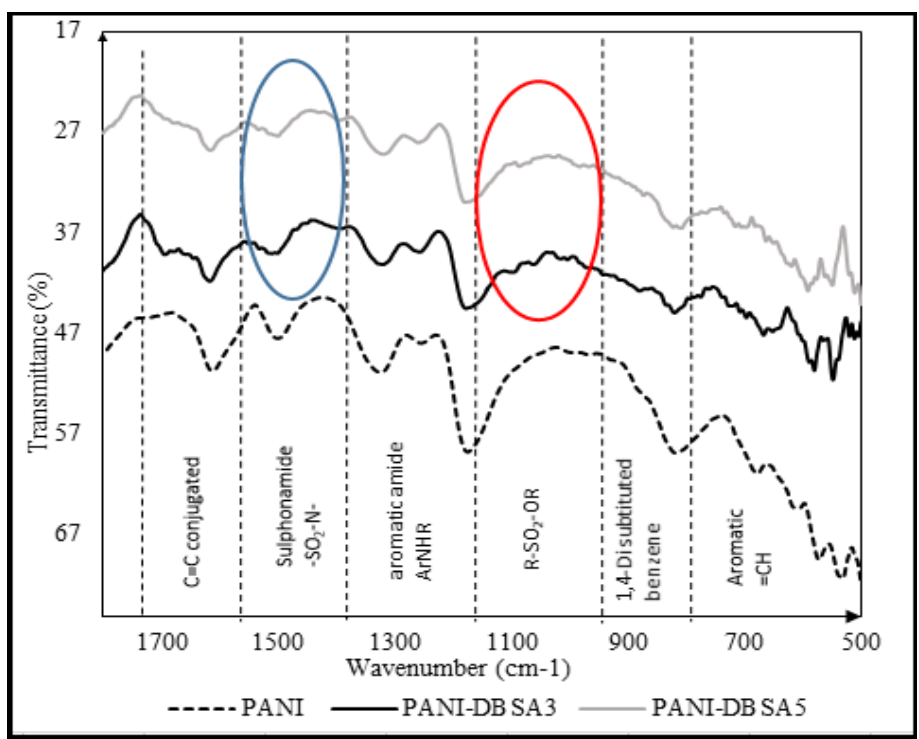

Figure 2. FTIR specra of Pristine PANI, PANI-DBSA 3 , and PANI-DBSA 5 .

Table 2. Comparision of absorption peaks in the synthesis pristine PANI, PANI-DBSA 3 and PANI-DBSA 5 .

\begin{tabular}{llccc}
\hline \multirow{2}{*}{ Functional Group } & \multicolumn{4}{c}{ Peaks $\left(\mathbf{c m}^{-\mathbf{1}}\right)$} \\
\cline { 2 - 5 } & Reference [6] & Pristine PANI & PANI-DBSA $_{\mathbf{3}}$ & PANI DBSA $_{\mathbf{5}}$ \\
\hline $\mathrm{C}=\mathrm{C}$ conjugated & $\sim 1600$ & 1608 & 1617 & 1612 \\
Sulphonamide $\mathrm{SO}_{2}$-N & 1380 & - & 1387 & 1389 \\
$\begin{array}{l}\text { Primary or secondary aromatic } \\
\text { amide ArNHR }\end{array}$ & $1360-1250$ & 1252 & 1254 & 1257 \\
$\begin{array}{l}\text { Covalent sulphonates, } \\
\text { R-SO2-OR }\end{array}$ & $1020-850$ & - & 1095 and 1059 & 1084 and 969 \\
1,4-Disubstituded benzene & $860-780$ & 814 & & 820 \\
\hline
\end{tabular}

\section{Conductivity}

Electrical conductivity of PANI doped with various concentration of DBSA were determined by using four point probe analysis and their values are shown in Figure 3. The highest conductivity after doping with DBSA is 13. $37 \mathrm{~S} / \mathrm{cm}$. The graph shows conductivity of pristine PANI decrease when $\mathrm{DBSA}_{1}$ is introduce to the polymerization system. It is may be due to the polymerization of PANI are disturbed and segmental molecule structure not properly arranged. Furthermore, after addition of 1.2 and $1.65 \mathrm{mmol}$ of DBSA, the trend shows by increasing of amount of DBSA, the conductivity is increased. Moreover, PANI-DBSA AND PANI-DBSA $_{4}$ shows almost similar value of

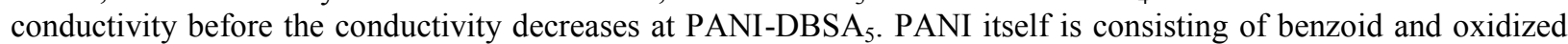
quinoid units [7]. The conduction of electricity in PANI is due to conjugation in the backbone of the polymer in the benzoid and quinoid units. Due to overlapping of conjugated $\pi$-electrons, there develops valance and conduction bands throughout the backbone of the PANI.

This can be explained as the presence of DBSA in polymerization, as "holder" to hold the aniline micelles monomer in aqueous medium as schematic representation shown in Figure 4. Aniline ion (phenyl- $\mathrm{NH}_{3}{ }^{+}$) resides between the individual sodium dodecyl sulphate (SDS) near the shell of micelle complexes with sulfate ion. The aniline molecule are oriented with phenyl substitution (hydrophobic nature of DBSA) to be the core of micelle and the $\mathrm{NH}_{3}{ }^{+}$to the outer side of micelle. During the polymerization process, the aniline ion is polymerized into the micelle 
together with DBSA after being oxidized by APS. Therefore, the increasing of amount of DBSA will increase the aniline ion attached together to formed a large size of micelle, hence enlargement of polymer chain. The longer chains of PANI formed, the higher conductivity of PANI as the present of large amount of the conjugated ion in the polymer chains. The formed chains also arranged in a segment, and the segmental local structure of polymer are shorten.

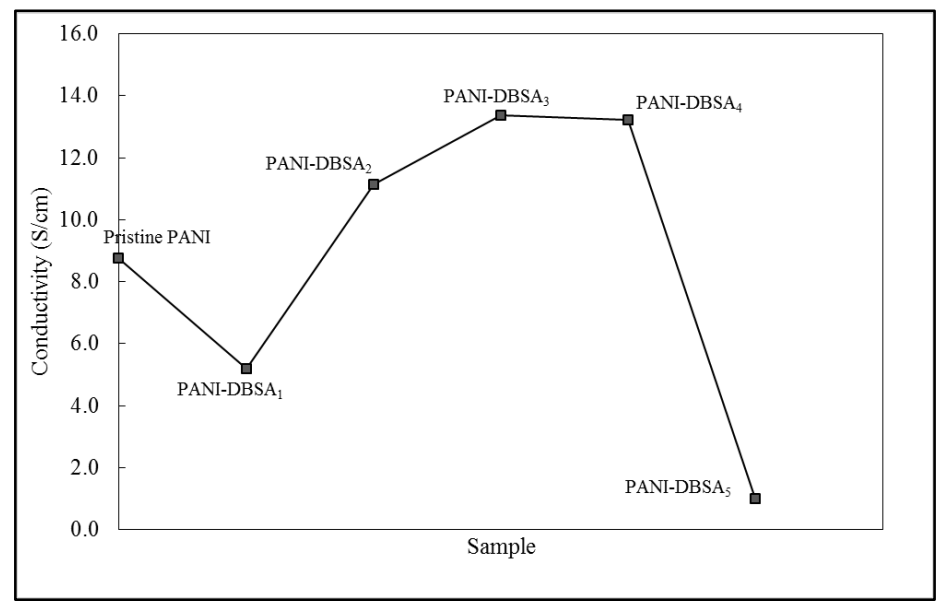

Figure 3. Conductivity of PANI-DBSA

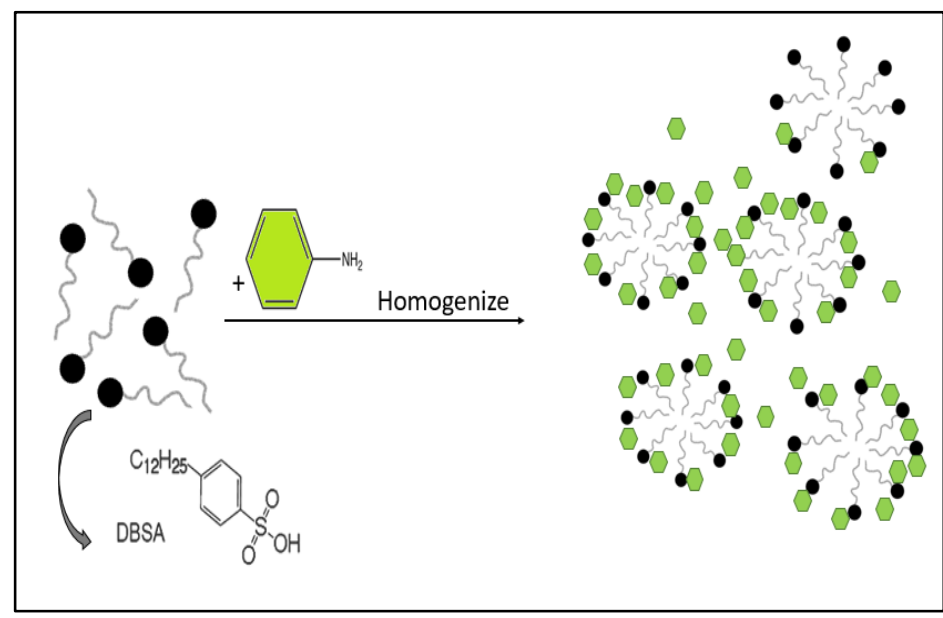

Figure 4. Probable reaction mechanism of micelles SDS and aniline during polymerization

On the other hand, the excessive amount of DBSA (as increased to 2.0 and $2.5 \mathrm{mmol}$ of DBSA) shows the decreasing in conductivity. It can be inferred that the DBSA also act as surfactant in the system. The excessive amount of sodium dodecyl sulphate (SDS) ion, will capture more aniline ion to be in one large micelle before oxidation occurs.

After addition of APS, the longer chains formed during oxidative polymerization process. However, as stated by Khohklov in 1981, the longer chains formed during polymerization, the higher possibility the polymer chains will collapse [8]. The collapse polymer chains or a Gaussian coil starts to aggregate, resulting in a homogeneously dense sausage-like shape. After several times, the minimization of interfacial area drives this sausage-like shape to 
$\begin{array}{ll}\text { Nurul Akmil et al: } & \text { DODECYLBENZENE SULFONIC ACID CONCENTRATION EFFECT ON ELECTRICAL } \\ \text { AND THERMAL PROPERTIES OF POLYANILINE TITLE IN ENGLISH }\end{array}$

condense and shorten until, at the final stage, a globule is formed [9]. The collapse phenomena creates chains disordered (globule) and resulting in dislocated of conjugated $\pi$-electrons hence lower the conductivity. The decrease in conductivity also could be assigned to the dominating role of ion association over free ion formation which decreases the number of charge carriers for conduction [10].

\section{Differential scanning calorimetry}

From DSC thermogram in Figure 5, we can determined the onset temperature of melting point, peak temperature that represent the melting point of the polymer, and the enthalpy of fusion, $\Delta \mathrm{H}$ by calculating area under the graph. Table 3 shows the DSC thermogram data for Pristine PANI and PANI-DBSA.

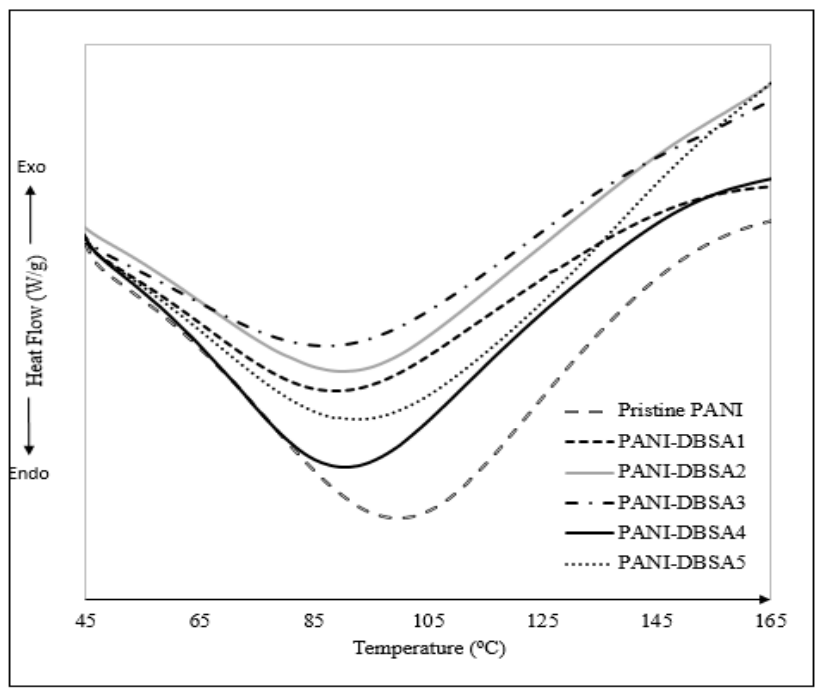

Figure 5. DSC thermogram of Pristine PANI and PANI-DBSAs

Table 3. DSC thermogram data for Pristine PANI and PANI-DBSA

\begin{tabular}{|c|c|c|c|}
\hline Sample & $\begin{array}{c}\text { Onset Temperature } \\
\left(\mathrm{T}_{0}\right),{ }^{0} \mathrm{C}\end{array}$ & $\begin{array}{l}\text { Melting temperature } \\
\qquad\left(\mathrm{T}_{m}\right),{ }^{\circ} \mathrm{C}\end{array}$ & $\begin{array}{c}\text { Enthalpy of Fusion } \\
(\Delta \mathbf{H}), \mathbf{J} / \mathbf{g}\end{array}$ \\
\hline Pristine PANI & 50.31 & 97.77 & 210.2908 \\
\hline PANI-DBSA $_{1}$ & 42.31 & 87.22 & 219.7509 \\
\hline PANI-DBSA $_{2}$ & 41.60 & 86.85 & 158.4879 \\
\hline PANI-DBSA $_{3}$ & 41.56 & 84.16 & 136.6957 \\
\hline $\mathrm{PANI}-\mathrm{DBSA}_{4}$ & 40.34 & 88.27 & 157.8515 \\
\hline PANI-DBSA $_{5}$ & 40.73 & 89.15 & 187.4384 \\
\hline
\end{tabular}

In semi-crystalline polymer like PANI, a broad melting curve is the normal DSC thermogram, thus make separating melting from simultaneous crystallization or crystalline reorganization can be difficult [10]. The onset temperature usually indicates the starting point PANI's molecules start to change their state from solid to rubbery state. The PANI's molecules become soften and crystalline portions start to move transitionally [11]. As increasing in amount of DBSA during polymerization of PANI, the onset temperature is decreasing shows the presence of DBSA has altered the chains length make it easily to adsorbed heat to disturb ordered molecule regions. Though, sample PANI-DBSA $_{5}$, shows the onset temperature increase slightly compare to PANI-DBSA because the differences is too small. The melting point of the pristine PANI and PANI-DBSAs shows the same trend as onset temperature. In addition of DBSA, the melting point slightly decreased compare to pristine PANI. 
In Figure 6, the enthalpy of fusion shows indirectly proportional to the value of conductivity. It can be enlightened that the amount of DBSA doped PANI affect the conductivity and thermal properties of PANI. The value enthalpy of fusion $(\Delta \mathrm{H})$ corresponds to the normalized peak area in joules per gram $(\mathrm{J} / \mathrm{g})$ and a result of crystal imperfection [12]. The increase in conductivity with $\Delta \mathrm{H}$ is interpreted in terms of hopping mechanism between co-ordination sites, local structural relaxation and segmental motion of polymer [13]. Thus the segmental local structures of polymer are shorten with increasing in amount of DBSA in polymerization of PANI. This can be assure as the $\Delta \mathrm{H}$ are decreasing as increasing in amount of DBSA. However, as concentration of DBSA is increase up to $2.0 \mathrm{mmol}$, the $\Delta \mathrm{H}$ shows slightly increased. This is may be due to the PANI local structure has been increased and the segmental motion are stiffer thus increase heat required to vibrate the PANI structure.

Moreover, increasing amount of DBSA shows no independent influence to melting point of PANI. This may be due to the amount of DBSA are very small to influence the melting point even though the $\Delta \mathrm{H}$ shows a great significant value.

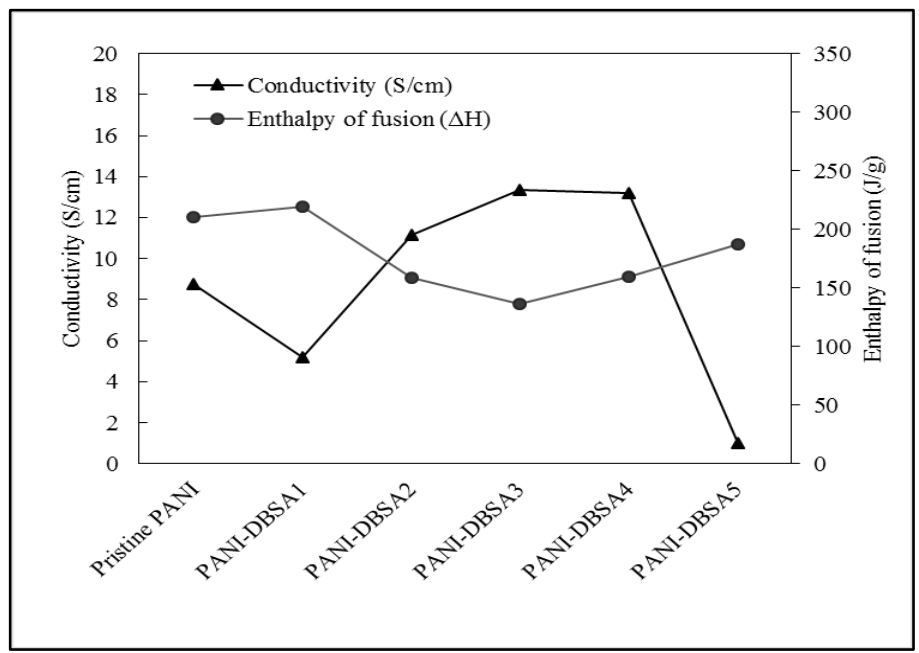

Figure 6. Graph of enthalpy and conductivity versus amount of DBSA in PANI

\section{Conclusion}

Polyaniline was prepared by chemical synthesis using DBSA as the surfactant. The spectra of PANI-DBSA has the important significant peaks of DBSA after doping procedure. For synthesized PANI-DBSA, FTIR spectra shows the dopant peaks as the interaction with PANI structure. The electrical conductivity measurement has shown that electrical conductivity of pristine PANI is $8.77 \mathrm{~S} / \mathrm{cm}$ and addition of DBSA as dopant in PANI polymerization has increased the conductivity up to $13.37 \mathrm{~S} / \mathrm{m}$. Based on DSC results, DBSA has a strong effect as it can lowered the $\Delta \mathrm{H}$ values of $\mathrm{PANI}_{-D B S A_{1}}$ to PANI-DBSA 3 but increases at PANI-DBSA $\mathrm{P}_{4}$ and $\mathrm{PANI}^{-\mathrm{DBSA}_{5}}$ as the doping give an effect on PANI molecular arrangement.

\section{Acknowledgement}

The support of the Ministry of Higher Education (Malaysia) for Mybrain15 scholarship is kindly acknowledged.

\section{References}

1. Basavaraja, C., Pierson, R., Kim, J. H. and Huh, D. S. (2008). Microscopic studies of polyaniline-poly-nisopropylacrylamide/alumina composites containing dodecylbenzene sulfonic acid. Bulletin of the Korean Chemical Society, 29(9): 1699 - 1704.

2. Skotheim, T. A. (1986). Handbook of Conducting Polymer, Marcel Dekker, New York. 
Nurul Akmil et al: DODECYLBENZENE SULFONIC ACID CONCENTRATION EFFECT ON ELECTRICAL AND THERMAL PROPERTIES OF POLYANILINE TITLE IN ENGLISH

3. Saini, P. and Choudhary, V. (2015). Structural, spectral and thermal properties of bulky organic sulfonic acids doped polyanilines and antistatic performance of its melt blend. Indian Journal of Pure \& Applied Physics, 53(5): $320-327$.

4. Wang, Y., Ji, H., Shi, H., Zhang, T. and Xia, T. (2015). Fabrication and characterization of stearic acid/polyaniline composite with electrical conductivity as phase change materials for thermal energy storage. Energy Conversion and Management, 98: 322 - 330.

5. Wallace, G. G., Spinks, G. M. and Teasdale, P. R. (1997). Conductive electroactive polymers; intelligent materials systems. Lancaster: Technomic.

6. Socrates, G. (2004). Infrared and Raman characteristic group frequencies: tables and charts. John Wiley \& Sons.

7. Molapo, K. M., Ndangili, P. M., Ajayi, R. F., Mbambisa, G., Mailu, S. M., Njomo, N., Masikini, M., Baker, P. and Iwuoha, E. I. (2012). Electronics of conjugated polymers (I): polyaniline. International Journal of Electrochemical Science, 7(12): 11859 - 11875.

8. Khokhlov, A. R. (1981). Theory of the polymer chain collapse for the d-dimensional case. Physica A: Statistical Mechanics and its Applications, 105(1-2): $357-362$.

9. Abrams, C. F., Lee, N. K. and Obukhov, S. P. (2002). Collapse dynamics of a polymer chain: Theory and simulation. EPL (Europhysics Letters), 59(3): 391.

10. Hatakeyama, T. and Quinn, F. X. (1999). Thermal analysis: fundamentals and applications to polymer science. , $2^{\text {nd }}$ Edition, John Wiley \& Sons.

11. Menczel, J. D. and Prime, R. B. (2014). Thermal analysis of polymers: fundamentals and applications. John Wiley \& Sons.

12. Pitchimani, R., Zheng, W., Simon, S. L., Hope-Weeks, L. J., Burnham, A. K. and Weeks, B. L. (2007). Thermodynamic analysis of pure and impurity doped pentaerythritol tetranitrate crystals grown at room temperature. Journal of Thermal Analysis and Calorimetry, 89(2): 475 - 478.

13. Imre, Á. W., Schönhoff, M. and Cramer, C. (2008). A conductivity study and calorimetric analysis of dried poly (sodium 4-styrene sulfonate)/poly (diallyldimethylammonium chloride) polyelectrolyte complexes. The Journal of Chemical Physics, 128(13): 134905.

14. Wang, Y., Ji, H., Shi, H., Zhang, T. and Xia, T. (2015). Fabrication and characterization of stearic acid/polyaniline composite with electrical conductivity as phase change materials for thermal energy storage. Energy Conversion and Management, $98: 322$ - 330.

15. Mustaffa, N. A., Ahsan, Q., Azam, M. A. and Abdullah, L. C. (2016). Effect of dodecylbenzene sulfonic acid dopant concentration on the synthesis of polyaniline. Jurnal Teknologi. 